\title{
Aluminum Clad Spent Nuclear Fuel Task 4: Performance of Aluminum SNF in Dry Storage Experiment Test Plan
}

Phil Winston

July 2018

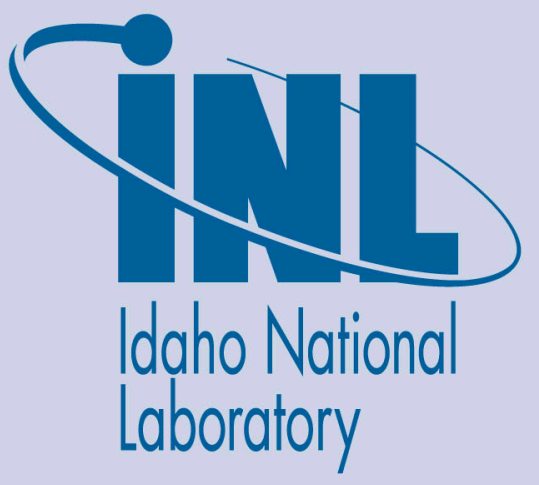

The INL is a U.S. Department of Energy National Laboratory operated by Battelle Energy Alliance 


\section{DISCLAIMER}

This information was prepared as an account of work sponsored by an agency of the U.S. Government. Neither the U.S. Government nor any agency thereof, nor any of their employees, makes any warranty, expressed or implied, or assumes any legal liability or responsibility for the accuracy, completeness, or usefulness, of any information, apparatus, product, or process disclosed, or represents that its use would not infringe privately owned rights. References herein to any specific commercial product, process, or service by trade name, trade mark, manufacturer, or otherwise, does not necessarily constitute or imply its endorsement, recommendation, or favoring by the U.S. Government or any agency thereof. The views and opinions of authors expressed herein do not necessarily state or reflect those of the U.S. Government or any agency thereof. 


\section{Aluminum Clad Spent Nuclear Fuel Task 4: Performance of Aluminum SNF in Dry Storage Experiment Test Plan}

Phil Winston

July 2018

Idaho National Laboratory Idaho Falls, Idaho 83415

http://www.inl.gov

Prepared for the

U.S. Department of Energy

Office of Environmental Management

Under DOE Idaho Operations Office

Contract DE-AC07-05ID14517 



\section{Aluminum Clad Spent Nuclear Fuel Task 4: Performance of Aluminum SNF in Dry Storage Experiment Test Plan}

INL/EXT-18-45861

July 2018

Prepared by:



$7 / 23 / 2018$

Date

Approved by:

Posma Panall

Josh Jarrell

INL Integration Lead

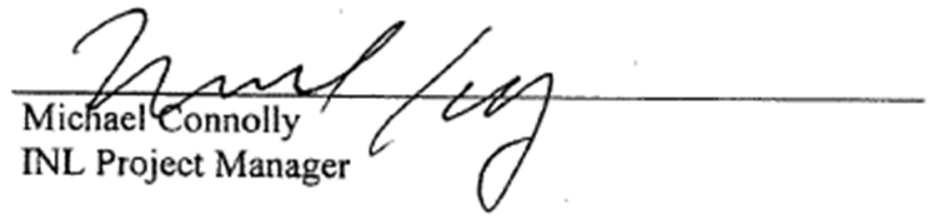

$7 / 23 / 2018$

Date

$8 / 30 / 2018$ 



\section{SUMMARY}

This document presents the activities to be performed in support of understanding the performance of aluminum spent nuclear fuel (ASNF) in dry storage. These activities will visually examine and acquire baseline samples of as-irradiated ATR fuel assembly components to determine fuel condition and the morphology of the aluminum oxyhydroxides present on the fuel external surfaces. Because the boehmite phase of oxyhydroxide is projected to be a significant contributor to radiolytic hydrogen production and general corrosion, being able to quantify its presence is of major importance to long term storage of aluminum spent nuclear fuel. Baseline samples will be taken from irradiated end adapters, removed from ATR SNF elements, stored in the ATR Canal. These will be transferred to Idaho National Laboratory (INL) Materials and Fuels Complex (MFC) to perform non-destructive and destructive testing to determine the degree of hydration of the wet-stored aluminum components prior to drying and air storage.

Examination of the dry stored SNF at Idaho Nuclear Technology and Engineering Center (INTEC) in CPP-603 Irradiated Fuel Storage Facility (IFSF) will allow the opportunity to identify gross degradation and as conditions permit, sample the surface oxide on fueled and un-fueled portions of the stored assemblies.

The information resulting from analysis of the ATR Canal samples will be used to support validation of surrogate samples prepared under Task 6, sample surrogate preparation, and used in Task 1, oxyhydroxide layer behavior and chemistry, Task 2, oxide layer radiolytic gas generation, and Task 5 , oxide layer response to drying. Surface oxide samples collected from SNF in IFSF dry storage will SNF dry storage prediction modeling from Task 3, sealed and vented system episodic breathing and gas generation prediction. 


\section{CONTENTS}







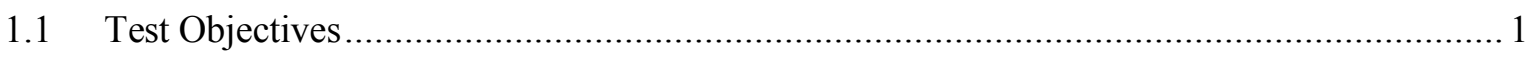



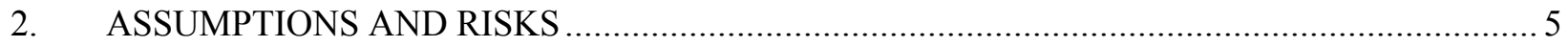

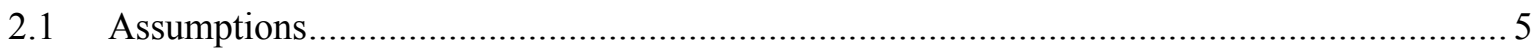

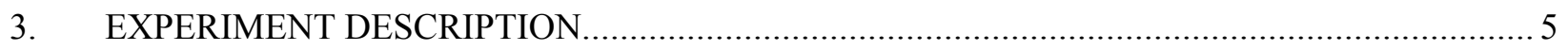



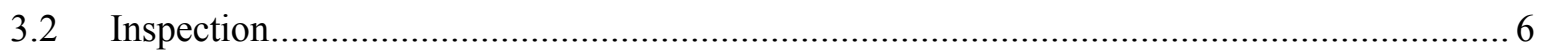

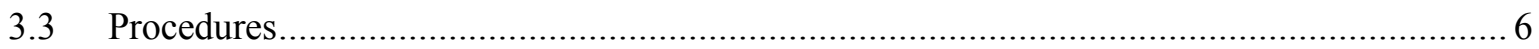

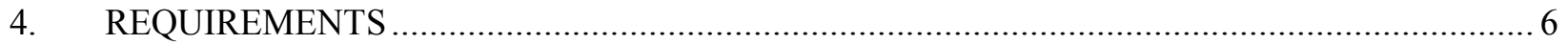

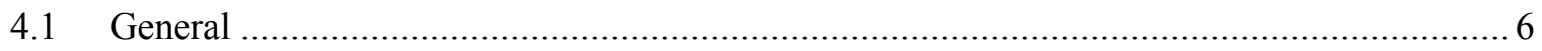

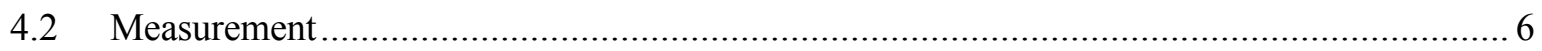

5. ENVIRONMENT, SAFETY, AND HEALTH ................................................................ 7

6. QUALITY ASSURANCE AND DATA/RECORD MANAGEMENT ….................................. 7

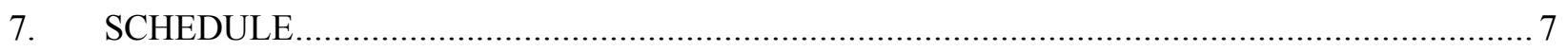



\section{FIGURES}

Figure 1. General Arrangement and cross section of ATR Fuel Assembly, 1a Lower and Upper

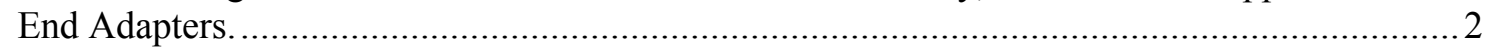

Figure 2. Identification of cutline section for endbox sampling. ........................................................... 3 


\section{ACRONYMS}

$\begin{array}{ll}\text { ATR } & \text { Advanced Test Reactor } \\ \text { BEA } & \text { Battelle Energy Alliance } \\ \text { CPP } & \text { Chemical Processing Plant } \\ \text { EDS } & \text { Energy Dispersive Spectroscopy } \\ \text { FIB } & \text { Focused Ion Beam } \\ \text { ICP } & \text { Idaho Cleanup Project } \\ \text { IFSF } & \text { Irradiated Fuel Storage Facility } \\ \text { INTEC } & \text { Idaho Nuclear Technology and Engineering Center } \\ \text { SEM } & \text { Scanning Electron Microscopy } \\ \text { SNF } & \text { spent nuclear fuel } \\ \text { TGA } & \text { Thermogravimetric Analyzer } \\ \text { WDS } & \text { Wavelength Dispersive Spectroscopy } \\ \text { XRD } & \text { X-Ray Diffraction }\end{array}$




\section{Aluminum Clad Spent Nuclear Fuel Task 4: Performance of Aluminum SNF in Dry Storage Experiment Test Plan 1. INTRODUCTION AND OBJECTIVES}

The activities performed in Task 4 are based on the recommendations by the Aluminum-Clad Spent Nuclear Fuel Sub Working Group, which were captured in the Aluminum Clad Spent Nuclear Fuel: Technical Considerations and Challenges for Extended (>50 Years) Dry Storage [1]. As identified in the 2017 report, Aluminum Clad Spent Nuclear Fuel Long Term Dry Storage Technical Issues Action Plan Technical and Engineering Activities [2], the conditions experienced by irradiated aluminum test reactor fuels following drying and extended storage may lead to degradation of the fuel integrity. The stability of the passive aluminum oxide surface on the fuel plates and any chemisorbed or physisorbed water in that layer is a factor in corrosive breakdown of the fuel assembly. Radiolysis of water in oxyhydroxides like boehmite may lead to oxidative corrosion of the aluminum. Knowledge of the chemical composition of the passive oxide layer and its oxyhydroxide content following drying and storage in air in unsealed canisters will allow predictive models to be developed for extended storage. Visual examination and physical sampling will provide baseline data to direct further research into the outcome of ultimately putting the fuel into sealed canisters for final disposition.

Challenges to predicting short and long-term behavior are: (1) temperature assisted crystallization; (2) environmentally assisted kinetics; and (3) effects of irradiation. Taking clear advantage of the small sample sizes and the microanalysis capabilities afforded by latest advances in (scanning) transmission electron microscopy will ascertain: (i) the crystallography of potential stable and metastable phases (e.g., $\mathrm{AlO}, \mathrm{Al}_{2} \mathrm{O}, \mathrm{Al}_{2} \mathrm{O}_{3}, \mathrm{AlHO}_{2}, \mathrm{Al}_{5} \mathrm{HO}_{8}, \mathrm{Al}(\mathrm{HO})_{3}, \mathrm{AlO}(\mathrm{OH})$ ); (ii) phase distribution with nanoscale resolution; (iii) chemistry and structure of potentially mixed phases formed during and thereafter heating or irradiation; (iv) effects of heating rates and temperatures on the evolution of materials; and (v) a report on the structural pathways for the continued evolution of aluminum in varying environments specifically to improve our management of spent nuclear fuel.

\subsection{Test Objectives}

Task 4 objectives include:

- A determination of spent aluminum research reactor fuel oxyhydroxide film thickness and composition prior to drying and vented canister storage in support of Task 1.

- A determination of general mechanical and physical status of dry stored aluminum fuel by visual examination.

- A determination of spent aluminum research reactor fuel aluminum oxyhydroxide film thickness and composition following drying and vented canister storage in CPP-603 IFSF.

\subsection{Task Description}

End adapters (end boxes) as shown in Figure 1a above are structures that are used to direct coolant flow and structurally locate the fuel assemblies in the core that are cut off of spent ATR assemblies prior to dry storage. Numerous of these end adapters have accumulated in the ATR canal. The available inventory has not been tracked to link the end adapters to irradiation history, so randomly selected items amounting to two sections from 5 upper and two sections from 5 lower adapters will be taken by sawing off approximately $1 / 2$ inch of the exposed end where the end box had been welded to the assembly side plates. This $1 / 2$ inch section will be at the transition point between the Type 6061 aluminum side plate and the Type 345 aluminum casting that is the end adapter. 

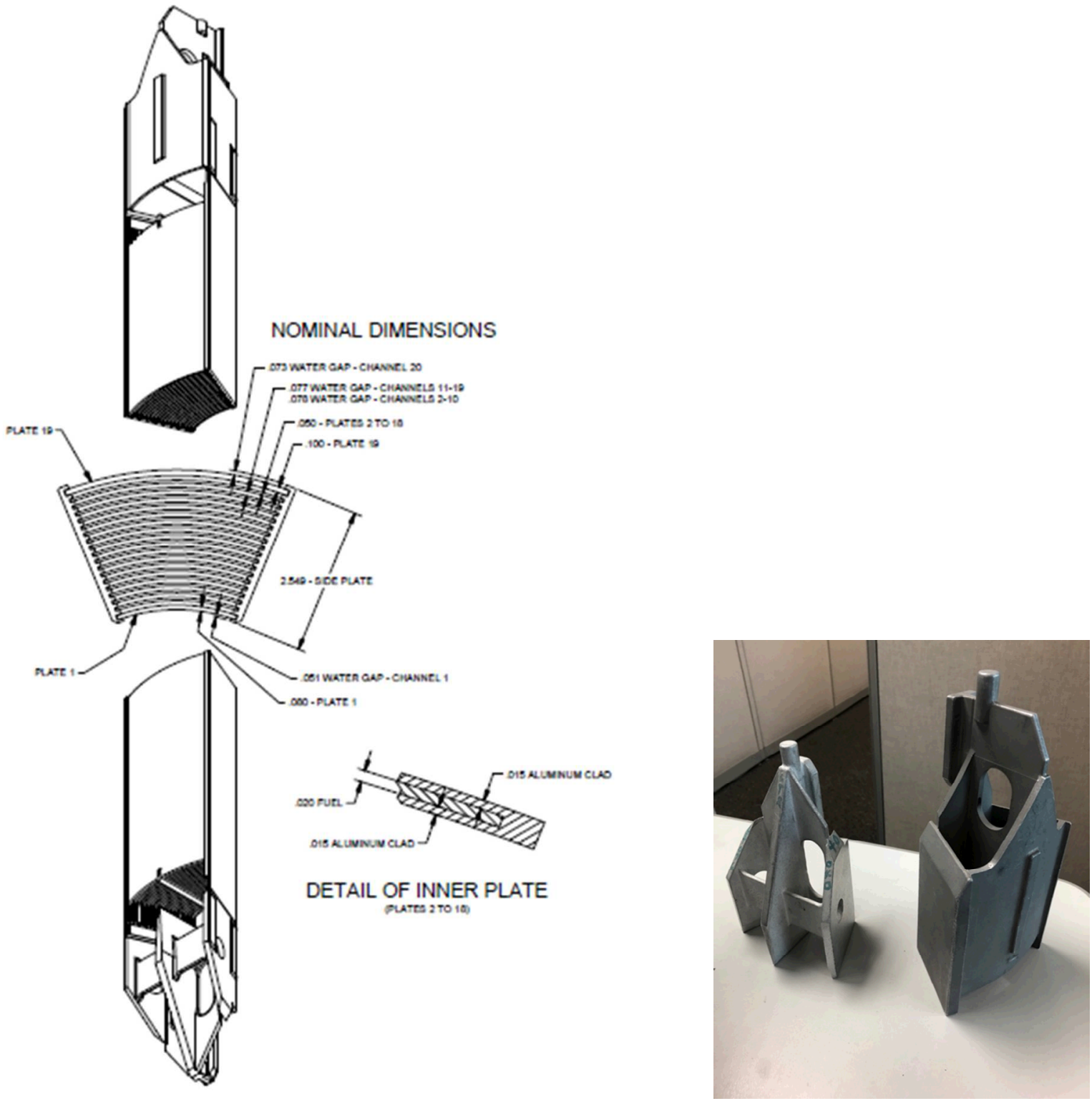

Figure 1. General Arrangement and cross section of ATR Fuel Assembly, 1a Lower and Upper End Adapters.

The samples will be measured using Scanning Electron Microscopy/Energy Dispersive Spectrometry (SEM/EDS) to confirm chemical composition to validate that the subsamples that are to be analyzed further are from the 6061 portion of the cut off. Figure 2 shows a mockup of the cut location on a 3D printed model endbox. Samples from both upper and lower endboxes will be taken. 


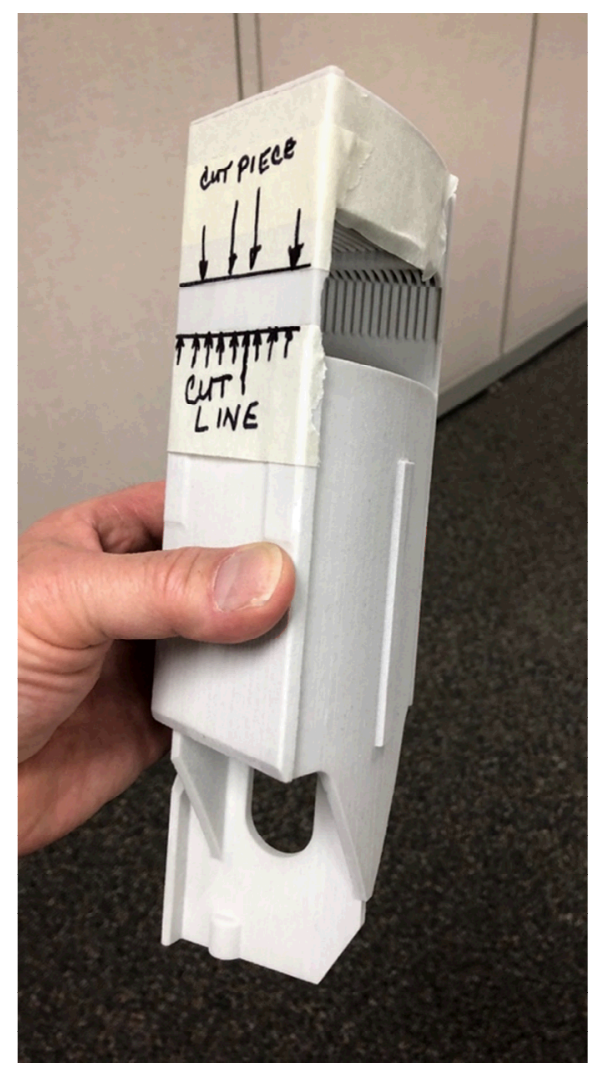

Figure 2. Identification of cutline section for endbox sampling.

The tasks to be performed are as follows:

1. Acquisition of samples prior to transfer to dry storage.

2. Analysis of the acquired samples to determine the oxyhydroxide composition.

Sampling and inspection of actual dry stored ATR assemblies will be performed at INTEC CPP-603 IFSF by Fluor Idaho personnel under contract to Battelle Energy Alliance (BEA). This work involves integration of the sampling effort into the fuel consolidation and repackaging activities that Fluor Idaho must perform in 2019. The consolidation is part of the change from wet receipt of ATR fuel in CPP-666 followed by transfer to CPP-603 to direct transfer from ATR to CPP-603. The sampling and inspection activity will occur when an ATR fuel bucket is placed in lag storage while its position in a canister is replaced by four 4-position buckets. The lag stored bucket will be placed in the well in front of the Fuel Handling Cave South window, and individual assemblies will be lifted from their bucket positions to approximately $75 \%$ of their length so that their surface can be inspected for mottling or surface distortion that would be indicative of radiolytically produced hydrogen bubble formation under the oxide layer. The general tasks will include:

1. Visual inspection of the accessible surfaces using high radiation-resistant cameras.

2. Acquisition of surface oxide samples using a BEA-developed surface scraper.

3. Analysis of the surface oxide samples to determine the oxyhydroxide composition

Analysis of the samples taken from the end boxes and those from dry stored fuel assemblies will be done using several facilities at the Materials and Fuels Complex including the Electron Microscopy Laboratory (EML) for initial SEM characterization and sample preparation, Irradiated Materials Characterization Laboratory (IMCL) for X-Ray Diffraction (XRD) to determine surface oxide morphology and Scanning Electron Microscopy/Focused Ion Beam (SEM/FIB) machining to remove surface samples to determine oxide layer thickness and chemical composition. 
Initial SEM characterization will include mounting samples to evaluate general surface variability and porosity as well as identify the oxide layer thickness from edge mounted samples. This information will be used to direct machining of Transmission Electron Microscope (TEM) sample lamellae using the FIB. Elemental chemical determination can be done using EDS.

FIB machining is guided by an SEM, which will allow identification of differences in the chemical character of the sample by EDS as the machining proceeds through the depth of the oxide layer.

XRD of the exposed surface of subsamples will identify the various crystal forms of the hydrated surface.

Sample Preparation and Focused Ion Beam Microscopy. A typical electron transparent lamella on the order of $15 \mu \mathrm{m}$ by $10 \mu \mathrm{m}$ in total area with total cross-section thickness of less than $90 \mathrm{~nm}$ is necessary to study the potential oxide layer formation on aluminum. Lifting out multiple samples from experimented material will provide additional insight into homogeneity of the sampled surface. Using several trenches provides insight into the oxide layer thickness. The oxide layer thickness can further be validated using X-ray diffraction techniques.

$X$-ray Diffraction Analysis. X-ray diffraction analysis can be used to provide a bulk analysis of the structure and chemistry of materials. This includes preferred texturing, presence of phases, film thickness, and roughness. Preferred texturing is identified by performing a 2-theta scan that identifies the preferred crystallographic orientation and subsequent phase chemistry. Additional analysis on the average film thickness can be resolved from the reporting on the peak-broadening value in rocking fashion or using Xray reflectivity. Rocking about a single crystallographic peak can differentiate a smooth film by observing the side-lobes at both sides of the Bragg-peak.

Scanning Transmission Electron Microscopy. Following FIB lift-outs, reporting on the present phases and their distribution can be studied in limited quantities by using transmission electron microscopy. Utilizing a nanometer size electron beam, simultaneous imaging, diffraction, and X-ray spectroscopy data is collected. By combining the chemical sensitivity of X-ray spectroscopy and nanobeam diffraction effects on the structure and phase of a material at the same or less resolution can be reported. In particular, report on the ratios of aluminum to oxygen, combined with simultaneously collected 2-dimensional electron diffraction patterns and atomic contrast imaging transcends complications of phase uncertainty by cross-validation of chemistry against structure and vice versa. Given the potential for crystallographic structures ranging from triclinic to cubic, providing these capabilities to validate this effort is invaluable for additional insights into potential experiments. 


\section{ASSUMPTIONS AND RISKS \\ 2.1 Assumptions}

Two primary assumptions are relevant to Task 4:

1. End box samples from ATR can be acquired without affecting surface oxyhydroxide condition.

2. Operating conditions at IFSF can accommodate handling of individual fuel assemblies for inspection and oxide sampling during the fuel consolidation activity.

Secondary assumptions include:

1. End box samples can be adequately analyzed at MFC to provide the necessary oxyhydroxide information.

2. Samples of exposed surfaces of dry stored aluminum fuel are representative of the complete assembly.

3. Boehmite decomposition effects can be observed visually using the cameras that are available in the IFSF Fuel Handling Cave.

Risks include, but are not limited to:

1. Surface contamination control may adversely affect the ability to detect different oxide forms by XRD.

2. Fluor Idaho may not be able to support fuel inspection due to equipment availability or schedule constraints.

3. Criticality safety analysis review may prohibit movement of fuel assemblies in the IFSF Fuel Handling Cave during the canister drying cycle.

\section{EXPERIMENT DESCRIPTION}

\subsection{Task 4 Sampling and Inspection}

Data acquired from samples and inspection in Task 4 will support the Task 6 production of surrogate samples. Discarded ATR assembly end boxes will be sectioned to provide samples of 6061 aluminum side plate material that can be analyzed to determine composition and morphology.

Analysis of the end box samples is proposed to include the following items:

1. X-ray diffraction to determine whether the prevailing oxyhydroxide is boehmite, bayerite, gibbsite or other morphologies. This analysis will be contingent on whether the radioactive surface contamination will preempt being able to perform the analysis on an instrument that is not fully enclosed in a hood or glovebox.

2. The subsamples of the parent material will be tested for rates of dehydration by placing them in the thermo-gravimetric analyzer. This testing will give values to indicate the degree of dehydration that fuel to be stored in IFSF that can be achieved using heated vacuum drying in the IFSF Conditioning Station. Use of the TGA will give data on the rates of dehydration and final state that may be achieved for vacuum drying efforts to be considered in Task 5 .

3. Analysis of surface chemical composition will be performed using a SEM Focused-Ion Beam to determine the depth of the oxide layer in a precise manner. FIB lamellae will be produced to be analyzed using the Scanning Transmission Electron Microscope (STEM), which will provide an indication of 3-dimensional differences in morphology throughout depth of the oxide layer.

4. Initial SEM scanning of the sample surface will also be done to determine variations in composition over the width of a sample and also do confirmatory analysis that the sample piece is of the Type 6061 alloy. 


\subsection{Inspection}

Because the ATR fuel that has been dry stored for more than a decade is managed under the Idaho Cleanup Project (ICP) by Fluor Idaho, it will be necessary to establish a contract for the services of Fluor personnel and resources. This contract will include evaluation of the SAR-114 safety basis regarding multiple fuel handling activities being performed in parallel in the INTEC CPP-603 IFSF Fuel Handling Cave. Due to Fluor Idaho contract priorities, fuel handling and oxide surface sampling will need to be done in a manner that does not interfere with completion of ICP milestone activities. This is a fundamental requirement that has been stated by Fluor Idaho personnel.

Because the ICP operations does not have a completed tool for handling and inspecting ATR assemblies, a design that was developed in 1998 will be evaluated for use at IFSF prior to fabrication by BEA. Structural and safety basis evaluation will be required. Once a tool design is accepted and fabricated, testing of the tool in mockup conditions will be needed to familiarize operators with its use and identify modifications that may need to be made to assure effective operation.

Addition of separate steps for lifting fuel assemblies out of their storage buckets will require evaluation of the appropriate sequence to eliminate interference that could create delays, affecting Fluor ICP milestone completion.

BEA will design and fabricate a tool(s) for acquisition of surface samples or bulk aluminum pieces that will be evaluated by Fluor safety analysis and engineering personnel. This tool will be tested to determine the depth of surface removal that is necessary to acquire a sample that has the properties of interest independent of the Fluor evaluation.

Once acquired, the samples will be packaged and transported to MFC EML for analysis by XRD and STEM if in powder form, and if discrete metal samples can be acquired from the sideplate stub, these will be mounted and imaged using SEM with chemical characterization by EDS.

\subsection{Procedures}

Samples at ATR Canal will be acquired in accordance with Work Order 257986, to be performed by Facility Welders. The samples will be acquired by use of a portable band saw to cut off a section at the nominal weld seam between the casting and the side plate.

Visual inspection at IFSF will be performed in accordance with Management Control Procedures with special instructions that allow secondary fuel handling during dwell steps of the consolidation process.

Analysis of the ATR canal and IFSF oxide samples will be done using the Laboratory Instructions specific to the instruments in use.

\section{REQUIREMENTS}

\subsection{General}

Radiological controls identified in the INL and ICP Radiological Program apply to all irradiated material handling, at ATR, MFC or INTEC.

Movement of fuel assemblies during visual inspection and sampling will be performed in accordance with the approved facility safety basis, SAR-114, to ensure that criticality safety limits are observed.

\subsection{Measurement}

Measurement of oxyhydroxide morphology by X-ray diffraction will be dependent on radiological control techniques for prevention of the spread of removable surface radiological contamination.

Measurement of oxyhydroxide film thickness will be performed using a FIB. A standard of aluminum plate with an identified thickness will be used as a comparison. 
Measurement using the TGA will provide an independent indication of the amount of heat input needed to dehydrate the oxyhydroxide surface film.

A minimum of 5 measurements will be made per sample to establish compositional and thickness variability.

\section{ENVIRONMENT, SAFETY, AND HEALTH}

All samples will be handled according to INL and ICP Industrial Hygiene and Industrial Safety requirements. Samples and generated material to be disposed will be tracked and disposed according to the directions of Waste Generator Services personnel.

\section{QUALITY ASSURANCE AND DATA/RECORD MANAGEMENT}

Sample data will be validated by use of blanks and calibration for each sensor technology prior to and following use.

\section{SCHEDULE}

\begin{tabular}{|l|l|}
\hline TASK 4 - Performance of ASNF in Dry Storage & 7/19/2018 \\
\hline Milestone 4.1: Characterize aluminum from the ATR canal & $\mathbf{9 / 3 0 / 2 0 1 8}$ \\
\hline Milestone 4.2: Develop individual ATR element handling capability for use in CPP-603 & $9 / 30 / 2019$ \\
\hline Milestone 4.3: ATR Element Visual Inspection & $9 / 30 / 2019$ \\
\hline Milestone 4.4: Surface Oxide Sampling Technique & $9 / 30 / 2019$ \\
\hline Milestone 4.5: Canister Monitoring Evaluation & \\
\hline
\end{tabular}

\section{REFERENCES}

1. M.D. Argyle, Aluminum Clad Spent Nuclear Fuel: Technical Considerations and Challenges for Extended (>50 Years) Dry Storage, DOE/ID RPT 1575, 2017.

2. M.J. Connolly, Aluminum Clad Spent Nuclear Fuel Long Term Dry Storage Technical Issues Action Plan - Technical and Engineering Activities, INL/EXT-17-43908, 2017. 